\title{
Sorption of fluorescent polystyrene microplastic particles to edible seaweed Fucus vesiculosus
}

Sundbæk, Kasper Bjerrum; Due Würtzner Koch, Ida ; Greve Villaro, Clara ; Rasmussen, Niclas Spangegaard; Løvstad Holdt, Susan; Hartmann, Nanna B.

Published in:

Journal of Applied Phycology

Link to article, DOI:

10.1007/s10811-018-1472-8

Publication date:

2018

Document Version

Peer reviewed version

Link back to DTU Orbit

Citation (APA):

Sundbæk, K. B., Due Würtzner Koch, I., Greve Villaro, C., Rasmussen, N. S., Løvstad Holdt, S., \& Hartmann, N. B. (2018). Sorption of fluorescent polystyrene microplastic particles to edible seaweed Fucus vesiculosus. Journal of Applied Phycology, 30(5), 2923-2927. https://doi.org/10.1007/s10811-018-1472-8

\section{General rights}

Copyright and moral rights for the publications made accessible in the public portal are retained by the authors and/or other copyright owners and it is a condition of accessing publications that users recognise and abide by the legal requirements associated with these rights.

- Users may download and print one copy of any publication from the public portal for the purpose of private study or research.

- You may not further distribute the material or use it for any profit-making activity or commercial gain

- You may freely distribute the URL identifying the publication in the public portal 


\section{Sorption of fluorescent polystyrene microplastic particles to edible seaweed Fucus vesiculosus}

Kasper Bjerrum Sundbæk ${ }^{\text {a }}$, Ida Due Würtzner Koch ${ }^{\text {a }}$, Clara Greve Villaro ${ }^{\text {a }}$, Niclas Spangegaard

Rasmussen ${ }^{\mathrm{a}}$, Susan Løvstad Holdt ${ }^{\mathrm{b}}$, Nanna B. Hartmann ${ }^{\mathrm{a}, *}$

${ }^{a}$ Department of Environmental Engineering, Technical University of Denmark, 2800 Kgs. Lyngby,

Denmark

${ }^{\mathrm{b}}$ National Food Institute, Technical University of Denmark, 2800 Kgs. Lyngby, Denmark

* Corresponding authors.

E-mail addresses: nibh@env.dtu.dk (N.B.Hartmann)

Published in: Journal of Applied Phycology

DOI:

\section{Acknowledgements}

We thank Susanne Kruse (Head of Laboratory Section), Sabrina Nedell Nissen (Laboratory Technician), and Sinja Rist (PhD student) for their valuable assistance during experiments. We also want to thank Eva Eriksson (former head of BSc programme) for discussion and sparring of the initial idea, Alexander Ventura (Gothenburg University) for inputs to statistical analysis and Bjarne Ottesen from Nordisk Tang / Nordic Seaweed for their interest in this study from a commercial point of view. 


\begin{abstract}
Increased global demands for food have raised interest for seaweed as a healthy and sustainable food source. At the same time, the large amounts of microplastic in the oceans have raised concern in relation to pollution of seafood including sea vegetables. The aim of this study was to examine sorption of fluorescent polystyrene (PS) microplastic particles to edible macroalga (seaweed) Fucus vesiculosus, and to investigate to what extent adsorbed PS particles could be washed off, using an industrial relevant method. PS microplastic particles (diameter of $20 \mu \mathrm{m}$ ) were used in a concentration of $2.65 \mathrm{mg} / \mathrm{L}$ (corresponding to 597 particles per $\mathrm{mL})$ in filtrated seawater $(50 \mathrm{~mL})$ to treat $F$. vesiculosus distal tips in blue cap flasks $(100 \mathrm{~mL})$ placed in a rotary box for $2 \mathrm{~h}$. Results showed sorption of PS microplastic particles to $F$. vesiculosus analysed by microscopy and a significant reduction of $94.5 \%$ by washing. These results were based on high microplastic concentrations, not comparable to natural conditions/concentrations. Nonetheless, this study provides methodological and mechanistic insights into procedures for investigating the sorption of microplastics to seaweed, for which there currently is no established standardised method.
\end{abstract}

Keywords: Macroalgae, Marine litter, Plastic debris, Adsorption, Sea vegetables, Bladderwrack 


\section{Introduction}

Multiple studies have addressed the global challenges of food scarcity and future food security, identifying human population growth as one of the key drivers (Grafton et al. 2015). In this context, the oceans are sources of vast resources and can play a key role in achieving an increased and sustainable food production. However, an estimated 268,940 tons of plastics are floating in the world's oceans today, of which part are present as microscopic plastic pieces, commonly referred to as microplastics (Eriksen et al. 2014). This plastic pollution is attributed to an ever-increasing use of plastic combined with poor waste management (World Economic Forum 2016; Jambeck 2015). This plastic pollution raises concerns of human exposure via food, although effects on human health are still largely unexplored and potential mechanisms of toxicity not yet well assessed (Wright and Kelly 2017).

Marine macroalgae (seaweeds) are often mentioned as superfoods (Petz 2016). Seaweeds are rich in polysaccharides, minerals, and certain vitamins (Arasaki and Arasaki T 1983), and contain bioactive substances like proteins (Kumar et al. 2008), and other compounds such as fucoxanthin and fucoidan, acting as antioxidants, anti-viral, anti-herpatitic, and anti-obesity substances (Holdt and Kraan 2011). Despite these benefits, seaweed aquaculture is not well established in the Western world (Petz 2016), but represents an area of potential for future applications and utilization. One of the most common seaweed species in Denmark is the edible brown seaweed Fucus vesiculosus (Mouritsen 2009). A previous study (Gutow et al. 2015) found that seaweeds may represent an efficient pathway for microplastics from the water to a marine snail, the benthic herbivore Littorina littorea. However, to this date no studies have explored the direct human exposure to microplastics from consumption of seaweed. An assessment of current exposure levels of microplastics to humans has been highlighted as a crucial step towards assessing the potential for impacts on human health (Wright and Kelly 2017). In this context, also knowledge on microplastics in edible seaweeds must be considered. The aim of the present study was, based on controlled laboratory experiments, to confirm the adherence of polystyrene (PS) microplastics to the seaweed as well as their discrete localization, to investigate the effect of washing procedures on PS 
removal, and to provide methodological and mechanistic insights that can feed into future studies on microplastic contamination of seaweed for e.g. human consumption.

\section{Material and methods}

\subsection{Collection of seaweed}

Entire plants of $F$. vesiculosus were collected the day before the experiment at Klampenborg, Denmark (55 46' 19.142" N; 12 35' 48.152" E) on May 22nd, 2017. The seaweed was placed in seawater from the site and transported to the laboratory to a dark room at $10{ }^{\circ} \mathrm{C}$, where the seaweed was placed in an aquarium with aeration, artificial light (fluorescent light tubes) and a 12h/12h dark/light regime.

\subsection{Materials and experiment set-up}

Green fluorescent PS microplastic particles (diameter: $20 \mu \mathrm{m}, 1 \%$ solid suspensions with a small amount of surfactant $(0.1 \%$ Tween 20$)$ and $2 \mathrm{mM}$ of sodium azide as an anti-microbial agent, density: $\left.1.06 \mathrm{~g} / \mathrm{cm}^{3}\right)$ were purchased from Phosporex Inc, (Cat. No. 2106Q).

For the experimental setup, the method applied by Gutow et al. (2015) was used as a starting point for the method developed. In addition, the method was further refined based on two initial trials conducted with F. vesiculosus and Fucus serratus (data not shown, since not fully comparable, due to changes and refinements in experimental setup).

Seawater collected at the site was filtrated through a $0.45 \mu \mathrm{m}$ filter to remove suspended particulate matter. Four reagent blue cap bottles $(100 \mathrm{~mL})$ were filled with $50 \mathrm{~mL}$ filtrated seawater (controls), while another four reagent bottles were filled with $50 \mathrm{~mL}$ PS test solution, consisting of filtrated seawater with fluorescent PS microplastic particles in a final test concentration of $2.65 \mathrm{mg} / \mathrm{L}$ ( 597 particles per $\mathrm{mL}$ ). 
Distal tips (area: 4-6.9 $\mathrm{cm}^{2}$ per side) of $F$. vesiculosus were selected based on the following criteria: two bladders, preferably a single tip, and measuring at least $2.5 \mathrm{~cm}$ from the cut surface to the distal end of the lamina. These were cut $0.5 \mathrm{~cm}$ from the bladders, as illustrated on Figure 1. Four pieces of $F$. vesiculosus were placed in each reagent bottle and the reagent bottles were sealed and placed in a rotary box (1 rpm) at $10{ }^{\circ} \mathrm{C}$ for 2 hours. Hereafter, the seaweed was removed from the bottles and excess water was removed by vigorously shaking the seaweed pieces about 4 times. This was considered more comparable to industrial procedures than e.g. drying by paper tissue dabbing. The number of fluorescent PS microplastic particles was manually counted at four transects (see Figure 1). Particles were quantified using a Zeiss Primo Star iLed fluorescence microscope (ex490/em520) with an objective of 10x magnification. The individual seaweed samples were identified and measured (transect lengths and total areas) by taking pictures that were subsequently analysed using the software ImageJ.

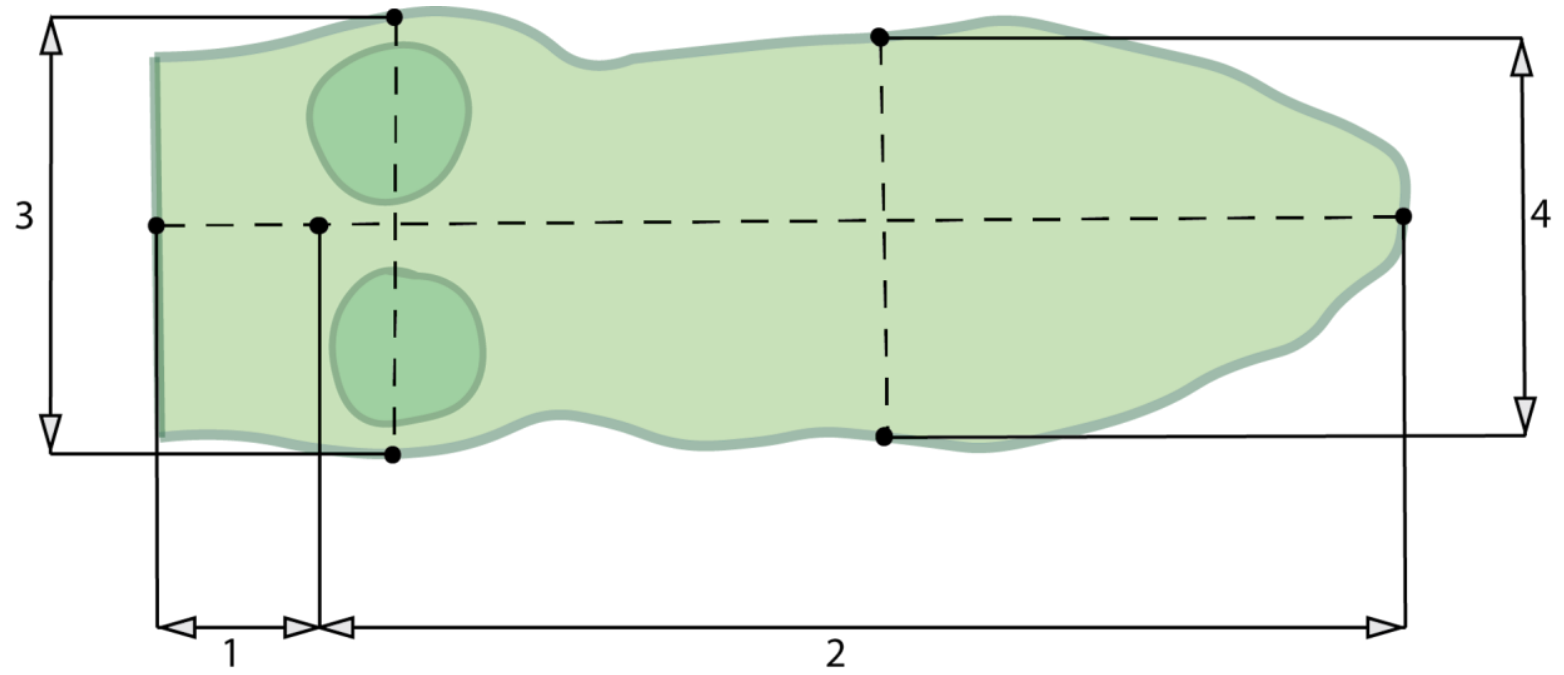

Fig. 1. The number of PS particles adhered to the surface of the seaweed $F$. vesiculosus was systematically assessed by counting the following transects: 1 ) Horizontally $0.5 \mathrm{~cm}$ from the cut surface to the beginning of the bladders, 2) Continuing the transect inbetween the bladders until the end of the laminar or when the laminar split, 3) Vertically over the bladders, starting from the top and down, 4) Vertically $2.5 \mathrm{~cm}$ from the distal tip starting from one side of the laminar to the other. 
For washing, the seaweed samples were hereafter placed in new reagent bottles ( $50 \mathrm{~mL}$ filtrated seawater) and these were agitated in the rotary box for 1 hour. After this washing treatment, the transects were counted again, as described above.

Wet weight was measured for all seaweed samples after removal of excess water. Dry weight was determined after drying the samples at $105^{\circ} \mathrm{C}$ for 19 hours (overnight).

\subsection{Statistics}

A two-way repeated measures ANOVA was performed on square root transformed data to fulfil the assumption of normality. The assumption of sphericity was met according to the Mauchly's Test. The test was performed using IBM® SPSS Statistics ${ }^{\circledR}$ software v. 25. Pairwise comparison, using Least Significant Difference (LSD) was performed to determine differences between transects with a significance level of $\mathrm{p}<0.05$.

\section{Results}

PS particles were observed on all transects of $F$. vesiculosus after exposure to microplastic dispersions, with an average of 2.63 PS particles per mm. After washing, the number of PS particles was reduced to an average of 1.07 PS particles per mm. Significant differences in PS adherence were seen between the different transects $(\mathrm{p}=0.001)$, with number of PS particles per length adhered to section 1 being significantly different from section 3 and 4 ( $\mathrm{p}=0.01$ and $\mathrm{p}=0.005$, respectively). There was no significant difference between section 1 and 2, however the p-value (0.075) was close to our 0.05 significance level. There was no significant interaction between factors $(\mathrm{p}=0.293)$. Fewer PS microplastic particles were present after washing, than after PS exposure for all transects (Fig. 2), as also confirmed by two preliminary experiments (data not shown). Overall, washing resulted in a significant reduction in adherent PS particles $(\mathrm{p}=0.022)$. No PS particles were observed on the control samples. Fewer microplastic 
particles were observed on the bladders, and more microplastic particles were observed between the bladders, during microscopy examination of transect 3 .

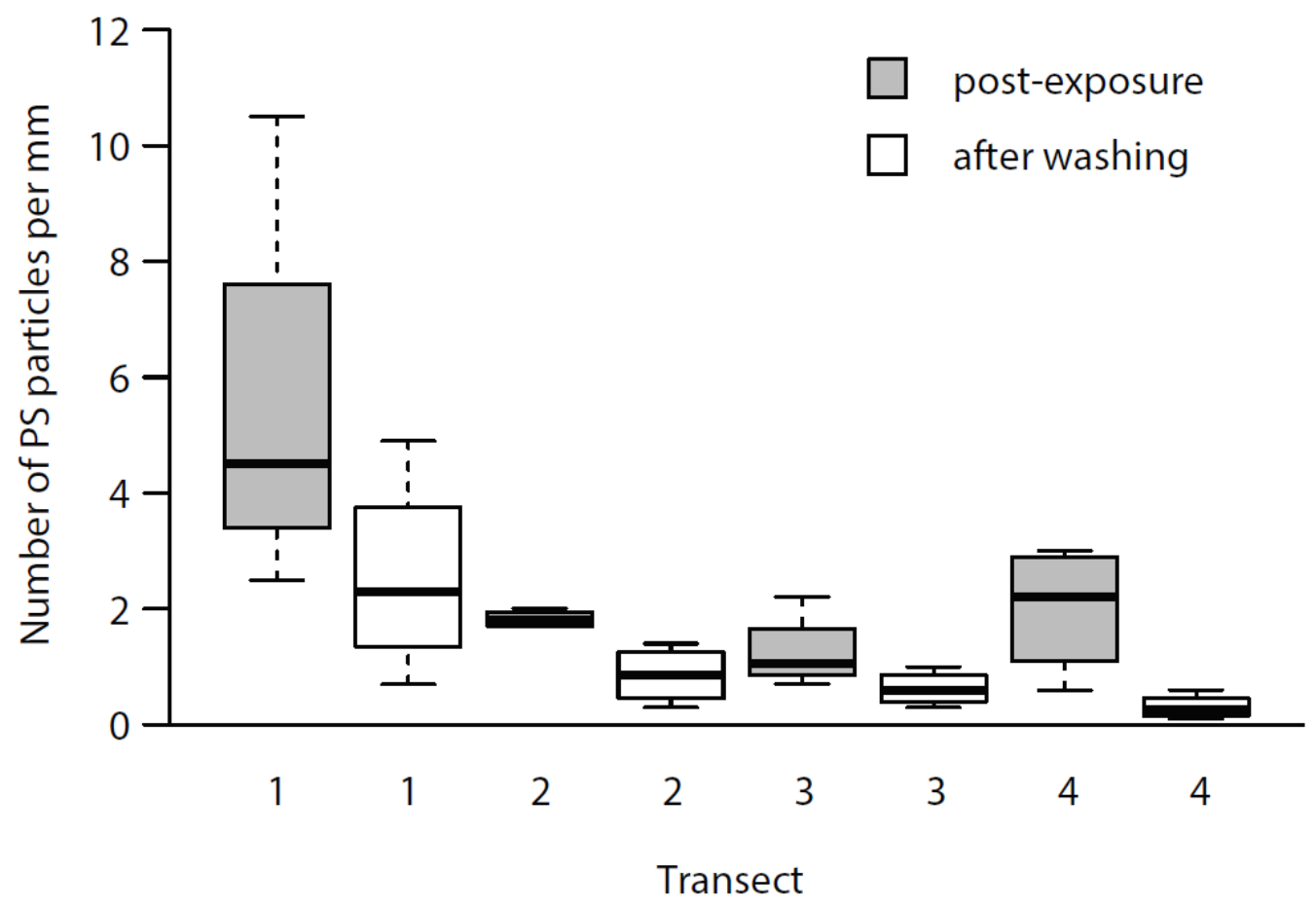

Fig. 2. PS Particles per length (mm) counted after PS exposure (grey) and after washing (white). The numbers 1-4 indicate the transects as illustrated in Figure 1.

The average of PS particles per length for transect 2 multiplied with average PS particles per length for transect 4 were used to estimate PS particles per area after PS exposure and after washing. On this basis, a concentration of 0.9-6.1 PS particles per $\mathrm{mm}^{2}$ (average: 3.99 PS particles per $\mathrm{mm}^{2}$ ) was estimated after PS exposure. Concentrations were reduced to 0.13-0.32 PS particles per $\mathrm{mm}^{2}$ (average: 0.22 PS particles per $\mathrm{mm}^{2}$ ) by washing, which correspond to an average reduction of $94.5 \%$. Based on these estimates (particles per $\mathrm{mm}^{2}$ ), the total surface of the distal tips (both sides) as well as weight measurements 251-639 PS particles per g wet weight (average: 515 PS particles per $g$ wet weight) and 1313-3590 PS particles per $g$ dry weight (average: 2,787 PS particles per g dry weight) remained on the seaweed after washing. 
Based on these numbers of adhered PS particles per $\mathrm{mm}^{2}$, the total fraction of adhered particles compared to the exposure concentration was calculated. The concentration of adhered paticles (0.9-6.1 and 0.13-0.32 PS particles per $\mathrm{mm}^{2}$, before and after washing, respectively) was multiplied with two times the average one-sided area of the distal tips $\left(6.9 \mathrm{~cm}^{2}\right)$, (as there are two sides of the lamina to which the particles adhere) as well as the number of pieces of $F$. vesiculosus in each reagent bottle (four). This number total estimate of adhered particles in each treatment bottle was then compared to the number of suspended particles in one reagent bottle (597 particles per $\mathrm{mL}$ ), giving an adherence of 17-112\% (average: 74\%) and $2.4-5.9 \%$ (average: $4 \%$ ) of the particles in the exposure suspension, before and after washing respectively.

\section{Discussion}

\subsection{Sorption of microplastic to seaweed-quantitative investigations}

Increased demands for food have raised interest in seaweed. At the same time there is a concern that the large amount of microplastic in the ocean (as described by e.g. Eriksen et al., 2014) might also pollute seaweeds. Results showed sorption of PS microplastic particles to $F$. vesiculosus, with an estimated average of 0.22 PS particles per $\mathrm{mm}^{2}$ remaining on the seaweed after washing.

A related study by Gutow et al. (2015) examined if seaweeds may represent an efficient pathway for microplastics from the water to the marine benthic herbivore L. littorea. In that study, pieces of $F$. vesiculosus were agitated for 2 hours in seawater $(40 \mathrm{~mL})$ with fluorescent microplastic particles $(1.4-55$ particles/mL). Subsequently the seaweed pieces were transferred into Petri dishes with filtrated seawater without microplastics (direct transfer or after stepwise water removal and drying), where they were agitated for an additional 2 hours (Gutow et al. 2015). In correspondence with the present study, results showed that microplastic adhered to the surface of $F$. vesiculosus and decontamination upon stepwise water removal and drying resulted in a significant loss of adherent particles (average reduction between 
55-75\%; Gutow et al. 2015). The results from this present study found on average 3.99 PS particles per $\mathrm{mm}^{2}$ before washing, which corresponds to an average sorption of $17-112 \%$ of the microplastic particles in the suspension. The resultof above $100 \%$ in one treatment bottle may be attributed to some uncertainty in the estimation of the total number of particles adhered to the surface of $F$. vesiculosus based on the transect values. However, it demonstrates that the main fraction of the particles were adhered to the lamina surfaces before washing. Gutow et al. (2015) found 0-0.06 (low PS concentration) and 0-0.15 (high PS concentration) particles per $\mathrm{mm}^{2}$ before washing. This corresponds to $16.1 \%$ and $20 \%$ of the PS particles in the suspension, respectively, being adsorbed to the surface of the seaweed.

These differences between the results of the two studies may be explained by the 10 -fold higher concentration used in this present study together with difference in exposure method. The focus of the present study was method development and improved mechanistic understanding. This may feed into future studies related to human food security and environmental pollutions. Hence, the target was not to investigate environmentally relevant concentrations. In addition, the study by Gutow et al. (2015) aimed to simulate natural processes (low tide) during washing procedures, achieved through gentle agitation in petri dishes. In the present study, the objective was on cleaning procedures of relevance to seaweed industrial processing as prior to human consumption. The higher reduction in PS particles after washing in this present study, compared to the study by Gutow et al. (2015), is likely because the seaweed had not been dried in-between exposure and washing, which is expected to ease the washing process. The higher percentwise adherence of particles in the present study (17-112\%) compared to Gutow et al. (2015) (16.1$20 \%$ ) may be related to the use of a rotary box, increasing the contact between the seaweed and the PS exposure suspension. 


\subsection{Sorption of microplastic to seaweed-mechanisms and localization}

In the present experiments, PS particles with a diameter of $20 \mu \mathrm{m}$ were used. Plant cells have micro channels with an exclusion size that limits uptake to $3 \mathrm{~nm}$ in diameter (Mezitt and Lucas 1996). Therefore, the PS particles are unlikely to translocate into the seaweed tissue.

Fucus vesiculosus is characterized by its phaeophycean hairs, which have the purpose of absorbing nutrients (Jormalainen et al. 2003). The presence of these hairs could contribute to the adherence of PS particles. Another characteristic of $F$. vesiculosus is its alginate rich cell walls, resulting in alginate release when cutting the seaweed (Martins 2013). Release of alginate is likely to influence the adherences of PS particles due to the gelatinous properties of this anionic polysaccharide substance. Supporting this suggestion, our results showed significant more PS particles at transect 1 near the cut surface. High occurrence of microplastic between the bladders generally suggested that some of the water still remained on the seaweed, potentially introducing an artefact when conducting the microscopically examination

The sorption of PS particles to the seaweed surface may also be influenced by the particle surface. Bhattacharya et al. (2010) studied the physical adsorption of $20 \mathrm{~nm}$ sized plastic particles onto a model cellulose film and living microalgal species Chlorella and Scenedesmus, whereas Nolte et al. (2017) studied the adsorption of 20-500 nm PS particles onto unicellular green alga Pseudokirchnerela subcapitata. Results of these studies suggested that neutral and positively charged PS particles possess a higher binding affinity, than negatively charged particles for the microalgae (Bhattacharya et al. 2010; Nolte et al. 2017). This was also consistent with the binding assay conducted with PS particles and the model cellulose film (Bhattacharya et al. 2010). Bhattacharya et al. (2010) hence stated that cellulose surfaces, which are slightly anionic, due to the presence of carboxyl group, play an essential role in initiating the binding between the algae and the plastics. It is therefore likely that for microplastics occurring in the environment, their affinity for algal surfaces (micro and macro) will depend on the specific properties and surface charges of both plastics and algae. 


\subsection{Recommendations for future studies}

This present study found a significant difference between particle adherence close to the cut surface (transect 1) and the other parts of the seaweed (transects 3 and4), likely due to alginate release from the cut surface. On this basis, it is recommended to exclude the surface area in the proximity of the cut surface in future estimations of particle adherence to seaweed. While it is faster to estimate the number of adhered particles per area by multiplying transects, it also gives rise to more uncertainty compared to actually counting all particles. At the same time, however, it allows for processing of more pieces of seaweed, potentially leading to more robust results. The choice of counting method may be selected based on exposure concentrations as well as the types of microplastic. When testing more environmentally realistic concentrations, counting the microplastics on the entire seaweed surface may be more appropriate. The study has shown that exposure conditions (agitation methods) likely influence the adherence of PS particles. This should be considered in future studies. Sample preparation techniques should also be further developed to avoid introduction of artefacts, which could lead to either over- or underestimation of PS adherence. Tests with different polymers and different surface charges are required to give a broader understanding of the potential transfer of microplastics to humans through edible seaweed. Finally, to further increase our knowledge on seaweed as a route of human exposure to microplastics, information is required on naturally occurring microplastic on wild-harvested and farmed seaweed. For this purpose methods are needed to extract the microplastics from the seaweed prior to analysis. This represents an important area of future research. 


\section{Conclusions}

This study shows sorption of PS microplastic particles to $F$. vesiculosus, as well as a significant reduction of $94.5 \%$ by washing. The results of this study contribute to uncover the mechanisms of the physical interactions between microplastic and seaweed, and propose a method for PS microplastic exposure and washing, combined with shaking for water removal and microscopy investigations. The results highlight a high degree of adherence of PS particles close to the cut surface, where they are likely 'trapped' in alginate. Also there are spatial variations in microplastic adherence on the algal surface, due to the physiological and topographical differences on the seaweed surface. Therefore, for future studies it is recommended to exclude the surface area in the proximity of the cut surface when observing the particle adherence to seaweed. Although the concentrations tested were much higher than environmentally relevant concentrations, results of this study feeds into the development of methods to quantify microplastic on seaweed. The applied method could be used to optimize cleaning procedures in seaweed processing, ensuring optimal removal of microplastics prior to human consumption of seaweed. 


\section{References}

Arasaki S, Arasaki T (1983) Low calorie, high nutrition vegetables from the sea to help you look and feel better. Japan Pubns, Tokyo..

Bhattacharya P, Lin S, Turner J P, Ke P C (2010) Physical adsorption of charged plastic nanoparticles affects algal photosynthesis. J Phys Chem C, 114:16556-16561.

Eriksen M, Lebreton L C M, Carson H S, Thiel M, Moore C J, Borerro J C, Reisser J et al (2014) Plastic pollution in the world's oceans: more than 5 trillion plastic pieces weighing over 250,000 tons afloat at sea. PLoS ONE 9: 1-15.

Grafton R Q, Daugbjerg C, Qureshi M E (2015) Towards food security by 2050. Food Secur 7:179-183.

Gutow L, Eckerlebe A, Gimenez L, Saborowski R (2015) Experimental evaluation of seaweeds as a vector for microplastics into marine foodwebs. Environ Sci Technol 50:(2), 915-923.

Holdt S L, Kraan S (2011) Bioactive compounds in seaweed: functional food applications and legislation. J Appl Phycol 23:543-597.

Jormalainen V, Honkanen T, Koivikko R, Eränen J (2003) Induction of phlorotannin production in a brown alga: defense or resource dynamics? Oikos 103:640-650.

Kumar CS, Ganesan P, Suresh PV, Bhaskar N (2008) Seaweeds as a source of nutritionally beneficial compounds-a review. J Food Sci Technol 45:1-13.

Martins M J F, Mota C F, Pearson G A (2013) Sex-biased gene expression in the brown alga Fucus vesiculosus. BMC Genomics 14:294. 
Mezitt L A, Lucas W J (1996) Plasmodesmal cell-to-cell transport of proteins and nucleic acids. In: Flipowicz W, Hahn T (eds) Post-Transcriptional Control of Gene Expression in Plants. Springer, Dordrecht, pp 251-273.

Mouritsen O G (2009) Tang - Grøntsager fra havet. Nyt Nordisk Forlag Arnold Busck, Copenhagen.

Nolte T M, Hartmann N B, Kleijn J M, Garnæs J, van de Meent D, Jan Hendriks A, Baun A (2017) The toxicity of plastic nanoparticles to green algae as influenced by surface modification, medium hardness and cellular adsorption. Aquat Toxicol 183:11-20.

Petz S (2016, Oct 03) Is seaweed the next superfood? marine biology professor says seaweed boom is already here. Telegraph-Journal. www.telegraphjournal.com; searched on 5 June 2017.

Wright S L, Kelly F J (2017) Plastic and human health: a micro issue? Environ Sci Technol. 51:66346647. 